\title{
Erratum to: Chapter 4: Changchun Across 1949: Rebuilding a Colonial Capital City Under Socialism in the Early 1950s
}

\section{Yishi Liu}

\section{Erratum to:}

China: A Historical Geography of the Urban

https://doi.org/10.1007/978-3-319-64042-6_4

This chapter was inadvertently published without reference/citation and the same has been updated.

The updated online version of this chapter can be found at https://doi.org/10.1007/978-3-319-64042-6_4

\section{Y. Liu $(\bowtie)$}

School of Architecture, Tsinghua University, Beijing, P. R. China 